\title{
Possibilidades para matematizar em aulas de Cálculo
}

André Luis Trevisan

Marcele Tavares Mendes

\section{Resumo}

Este artigo apresenta o relato de uma experiência em organizar um ambiente de aprendizagem para a disciplina de Cálculo Diferencial e Integral na qual buscamos oferecer aos estudantes a possibilidade de matematizar. Nossa experiência em sala de aula corrobora a ideia de ruptura de um contrato didático segundo o qual o estudante responde apenas questões após a explicação da teoria pelo professor.

Palavras-chave:Educação Matemática, Educação Matemática Realística, Cálculo Diferencial e Integral, Matematização.

\section{Abstract}

This paper presents an experience in organizing a learning environment for the discipline of Differential and Integral Calculus in which we offer to students the opportunity to mathematizing. Our experience in the classroom supports the idea of rupture of a didactic contract under which the student answers questions only after an explanation of the theory by the teacher.

Keywords: Mathematics Education, Realistic Mathematics Education, Differential and Integral Calculus, Mathematization. 


\section{Introdução}

O paradigma da Educação Superior, em especial na Educação Tecnológica, ainda se encontra baseado em modelos tradicionais de ensino, nos quais o professor apresenta os conteúdos aos estudantes e dá informações ou instruções de como resolver exercícios-tipo por meio de aulas expositivas. Neste cenário, as competências desenvolvidas pelos alunos restringemse às habilidades de reprodução e memorização, muitas desaparecendo logo após a realização das avaliações (grande parte delas de rendimento escolar).

Em particular nas aulas das disciplinas da área de Matemática, a prática pedagógica de muitos dos professores envolvidos com os diferentes cursos da Educação Tecnológica é comum: os professores usam o mesmo plano de ensino para disciplinas de mesma ementa em cursos diferentes, ou seja, mesma distribuição do programa, mesma metodologia, mesmos livros, mesmos instrumentos de avaliação, sem levar em consideração as idiossincrasias de cada curso.

Atrelado a isso, deparamo-nos com altos índices de evasão e reprovação em disciplinas de Cálculo Diferencial e Integral, nos muitos cursos na qual essa disciplina faz parte do currículo. Diante dessa realidade que vivenciamos na Universidade Tecnológica Federal do Paraná, câmpus Londrina e câmpus Apucarana, propomo-nos neste artigo a apresentar o modo que temos buscado organizar as aulas de Cálculo: um ambiente de aprendizagem que possibilite ao estudante o desenvolvimento de habilidades de conexão e reflexão, para além da mera reprodução e memorização.

Tal proposta é baseada nos pressupostos da Educação Matemática Realística, preconizada por Hans Freudenthal (1905-1990), e que valoriza a ideia da matemática como atividade humana. Para esse matemático holandês, a matemática consiste na atividade de organizar matematicamente a realidade e o aprender matemática está diretamente ligado a fazer matemática, na busca da solução de problemas.

Tais ideias vão ao encontro dos trabalhos desenvolvidos pelo GEPEMA - Grupo de Estudos e Pesquisa em Educação Matemática e Avaliação (Universidade Estadual de Londrina), grupo do qual os autores fazem parte, e que tem buscado compreender, por meio da análise de sua produção escrita, de que modo estudantes e professores lidam com tarefas de Matemática.

\section{Possibilidades para uma aula de Cálculo}

Nos modelos tradicionais de ensino de Cálculo, os objetos matemáticos primeiro são apresentados, desvinculados de qualquer situação contextual, com o intuito de serem utilizados ao final da sequência didática para resolver problemas de aplicação. Nesta perspectiva, a matemática é considerada como uma ciência acabada, a-histórica e organizada logicamente, seu 
ensino é visto como transmissão de conteúdos e a aprendizagem como a acumulação de conhecimentos.

Um professor que se considera um transmissor de conhecimentos, em geral, acredita que ensinar reside em transmitir informações, aprender é memorizar informações e conhecer é o acúmulo dessas informações. Esse professor restringe o aprendizado matemático ao que Buriasco (1999, p.38) aponta como "mera aquisição de um conjunto de procedimentos passo - a - passo, de algoritmos, de automatização de fórmulas, sem que haja a compreensão do processo como um todo e muito menos a apropriação do conteúdo matemático". Um esquema que pode se enquadrar às aulas de professores com tais concepções é representado no Quadro 1, retirado de Buriasco (1999, p. 49).

\begin{tabular}{|l||}
\hline 1) O professor explica a matéria (teoria). \\
\hline 2) O professor mostra exemplos. \\
\hline $\begin{array}{l}\text { 3) O professor propõe “exercícios" semelhantes aos exemplos dados para que os alunos } \\
\text { resolvam. }\end{array}$ \\
\hline 4) O professor (ou um aluno) resolve no quadro de giz os exercícios. \\
\hline $\begin{array}{l}\text { 5) O professor propõe aos alunos outros “exercícios" já não tão semelhantes aos exemplos que } \\
\text { ele resolveu. }\end{array}$ \\
\hline 6) O professor (ou um aluno) resolve os exercícios no quadro de giz. \\
\hline 7) O professor propõe "problemas", se for o caso, ou mais "exercícios". \\
\hline 8) Correção dos "problemas" e/ou dos “exercícios". \\
\hline 9) O professor começa outro assunto. \\
\hline \hline
\end{tabular}

Quadro 1 - Modelo de uma aula expositiva tradicional.

As aulas de Cálculo baseadas nesses moldes/protótipos são preparadas (quando são), sem preocupação com aquilo que os estudantes já sabem e com as idiossincrasias da turma, do curso, da instituição. Neste cenário não se estabelece um diálogo, para nós um elemento fundamental em processos de ensino e de aprendizagem, e não se estreita a relação da produção de significados com o contexto do profissional do curso. Reis (2001, p.21), sem a intenção de achar um culpado para a atual situação do ensino de Cálculo, compara uma aula de Cálculo com uma peça de teatro:

"de um lado, os atores (professores) atuando em uma peça mal ensaiada e mal dirigida, fazendo com que o público (alunos), de outro lado, não capte sua mensagem e se retire antes do último ato. De quem é a culpa no palco da sala de aula? Dos atores e sua má performance ou do público e sua insensibilidade? Ou seria do diretor?"

Em contrapartida, defendemos propostas de ensino que concebam a Matemática como uma ciência dinâmica construída pelos homens ao longo de sua história em resposta às demandas sociais de cada época. Tais propostas vêm ao encontro de uma educação em que o conhecimento é construído por meio de interações sociais, na qual os sujeitos envolvidos estabelecem relações 
entre os objetos da Matemática e seus cotidianos, entre eles e outras disciplinas e diferentes temas.

Em conformidade com a Educação Matemática Realística, é desejável que a Matemática esteja conectada à realidade, seja pertinente à sociedade e que o professor propicie aos estudantes a oportunidade para que eles próprios possam desenvolver matemática (Freudenthal, 1991). Nesse sentido, o foco do processo de ensino e aprendizagem não deve estar na Matemática como ciência, mas no processo de matematizar, ou seja, organizar a realidade usando ideias e conceitos matemáticos.

Assim, é desejável que o ambiente de sala de aula oportunize ao estudante se colocar num contexto em que seu compromisso com a aula de Matemática transpasse o desenvolvimento fragmentado, mecânico e reprodutor de habilidades, para que possa tornar-se o condutor do próprio processo de aprendizagem, por meio de tarefas que suscitem habilidades que abrangem níveis de conexão e de reflexão.

Para De Lange (1999), uma tarefa que envolve informações de linhas curriculares diferentes, que requer a decodificação e interpretação de linguagem simbólica e formal, entendendo suas relações com a linguagem natural, ou ainda, diferentes representações de um mesmo problema, se enquadra no conjunto de tarefas ditas de "conexão". Este nível inclui, além da formulação e solução dos problemas e situações, o desenvolvimento de estratégias e a previsão e verificação de soluções.

Já uma tarefa de reflexão requer que os estudantes analisem, interpretem, desenvolvam seus próprios modelos e estratégias e, apresentem argumentos matemáticos incluindo provas e generalizações. Com tarefas desse nível de habilidade os estudantes são convidados a matematizar.

Para autores da Educação Matemática Realística é relevante escolher boas tarefas que propiciem a organização de um ambiente de aprendizagem autêntico. Segundo Van Den HeuvelPanhuizen (1996) é desejável que os problemas permitam que o processo de aprendizagem seja transparente para os professores e para os estudantes, oportunize ir de habilidades básicas para o pensamento de ordem superior, sejam familiares aos estudantes, ofereçam possibilidades para a matematização e sejam resolvíveis de formas diferentes e em diferentes níveis.

Cabe ao professor organizar um ambiente de aprendizagem com tarefas que propiciem aos estudantes a "chance" de aplicar a matemática de forma flexível, em situações que sejam significativas para eles e que tais tarefas sejam o veículo por meio do qual o professor ensine e possibilite a aprendizagem aos seus estudantes. Enfim, que oportunize aos estudantes matematizar. 


\section{Organizando um ambiente de aprendizagem}

À luz do referencial teórico constituído, sentimo-nos desafiados organizar em nossas aulas de Cálculo ambientes que ofereçam aos estudantes possibilidades para matematizar, para "reinventar" matemática. Nosso intuito é propiciar aos estudantes tarefas para além das habilidades de reprodução e memorização, habilidades abrangendo níveis de conexão e de reflexão.

Tarefas que possibilitam explorar a intuição e a capacidade de organizar matematicamente situações que sejam "realizáveis", para que guiado pelo professor, os estudantes possam construir conceitos formalizados referentes aos tópicos do curso de Cálculo Diferencial e Integral. A título de exemplo, trazemos neste artigo a descrição do modo como organizamos uma sequência de aulas em que se objetivou explorar de forma intuitiva os conceitos relacionados ao comportamento final de uma função. $\mathrm{O}$ trabalho foi desenvolvido em turmas de Cálculo Diferencial e Integral I de cursos de Licenciatura e Engenharia da UTFPR nos câmpus Apucarana e Londrina da UTFPR.

Nossa experiência com turmas de Cálculo tem mostrado que a abordagem da disciplina partindo da exploração desconexa das várias famílias de funções, ou dos conjuntos numéricos e do conceito de módulo, ou ainda, contextos que se mostram distantes das situações exploradas por alunos oriundos do Ensino Médio (como o cálculo da inclinação da reta tangente e de áreas como motivações iniciais ao estudo de limites) e que pouco (ou mesmo nada) tem contribuído para que os estudantes construam algum significado para esses conceitos.

Assim, ao invés de iniciar o curso de Cálculo "derramando" uma série de conceitos "prontos e acabados", optamos por provocar o que Silva et al (2002) chama de "ruptura de cláusula do Contrato Didático", segundo o qual o estudante "só dá respostas às questões após a explicação da teoria pelo professor", instigando-os a buscar soluções utilizando recursos e conhecimentos que já possuíam.

A situação-problema que serviu como ponto de partida do trabalho, adaptada de Santos e Bianchini (2001), foi a seguinte:

Um tanque contém 5000 litros de água pura. Água salobra contendo $30 \mathrm{~g}$ de sal por litro de água é bombeada para o tanque, a uma taxa de $25 \mathrm{~L} / \mathrm{min}$. Mostrar que a concentração de sal no tanque após $t$ minutos (em $\mathrm{g} / \mathrm{L}$ ) era dada por

$$
C(t)=\frac{30 t}{200+t}
$$

Nossos objetivos a partir dessa situação-problema eram: explorar o conceito de função como uma relação entre duas variáveis; explorar a construção do esboço de um gráfico; apresentar as funcionalidades e deficiências de um software na construção de gráfico de funções (no caso, o Geogebra); explorar ideias que fundamentam a definição de assíntota horizontal; 
definir limites no infinito e "preparar terreno" para uma posterior definição precisa de limites. A proposta de exploração foi desenvolvida ao longo de cinco encontros (duas aulas cada).

Divididos em equipes com três integrantes, os estudantes receberam no primeiro encontro uma folha impressa contendo a situação-problema e foram orientados a buscar uma solução utilizando recursos e conhecimentos que já possuíam. Enquanto trabalhavam, foi possível identificarmos algumas das estratégias que as equipes desenvolviam na tentativa de apresentar uma solução ao problema, orientando e sugerindo possíveis encaminhamentos.

Embora ao fim do tempo combinado nenhuma equipe havia chegado à expressão sugerida no enunciado, alguns estudantes foram solicitados a compartilhar as estratégias que haviam desenvolvido, o que possibilitou a muitas equipes compreender o que efetivamente era pedido no enunciado, bem como recordar o conceito de concentração de uma solução, oriundo das aulas de Química do Ensino Médio.

Apesar disso, não parecia muito direto àqueles estudantes a busca de um padrão, que resultaria na construção da fórmula solicitada no enunciado. De certo modo, já prevíamos que isso aconteceria e optamos por organizar alguns questionamentos que, possivelmente, norteariam os estudantes, que foram apresentados num terceiro momento da aula:

- Qual será a quantidade de água no tanque, em litros, após 1 minuto? E após 2 minutos? E após 3 minutos? E após t minutos?

- Qual será a quantidade de sal no tanque, em litros, após 1 minuto? E após 2 minutos? E após 3 minutos? E após t minutos?

Tais questionamentos foram propostos com o intuito de fazer com que os estudantes percebessem que uma expressão geral poderia ser construída para representar a quantidade de sal e a quantidade de água no tanque depois de um tempo qualquer. A partir daí, tendo em vista que a concentração é calculada como a razão da quantidade de sal pela quantidade de água no tanque num instante qualquer, chegariam à expressão solicitada inicialmente.

Várias equipes chegaram à expressão

$$
C(t)=\frac{750 t}{5000+25 t}
$$

mas não à expressão (1), pedida no enunciado do problema. Nesse momento, mostrou-se necessária uma intervenção do professor, retomando a ideia de simplificação de uma expressão algébrica.

Numa quarta e última etapa, os estudantes foram solicitados a esboçar um gráfico relacionando tempo e concentração de sal, utilizando uma tabela de valores. Por tratar-se de um modelo diferente das funções elementares estudadas até aquele momento, a ideia inicial foi que 
graficamente a função pudesse ser representada por uma reta, e que a concentração seria sempre maior quanto maior fosse o tempo, segundo alguma constante de proporcionalidade.

Sabemos que conceitos podem ser retomados e novos conteúdos apresentados por meio de problemas. Uma vez que tínhamos em mãos uma situação na qual se descrevia uma quantidade (concentração de sal no tanque) dependendo de outra (tempo), dedicamos o segundo encontro ao desenvolvimento do conceito de função, as maneiras usuais de representá-la (verbalmente, numericamente com tabelas, geometricamente com gráficos, algebricamente com fórmulas). Ao discutirmos gráficos de funções, os estudantes foram instigados a descrever a técnica que utilizaram para construir o gráfico na aula anterior.

Esse foi o ponto de partida para o terceiro encontro. Nesse dia, os estudantes foram até o laboratório de informática, e lhes foi apresentado o software Geogebra e os comandos associados à construção do gráfico de uma função. Foi sugerido que construíssem o gráfico da função em tela utilizando a janela de inspeção padrão do Geogebra. Em seguida, foi solicitado que fizessem testes alterando essa janela de visualização, escolhendo intervalos de variação "muito grandes", e que descrevessem com suas palavras o comportamento observado.

A ideia inicial de que o gráfico seria uma reta e que a concentração seria sempre maior quanto maior fosse o tempo é então derrubada, e observar que a função "estabiliza-se" a partir de certo instante foi uma surpresa para muitos estudantes. De um ponto de vista informal, puderam perceber que os valores da função tornam-se tão próximos de um número $L$ quanto queiramos, à medida que a variável independente cresce sem parar.

Discussões sobre a escolha da janela de inspeção, a distorção na proporção da aparência, os erros de amostragem e as lacunas falsas (ANTON et al, 2007) mostraram-se bastante pertinentes àquele momento.

O estabelecimento de que o número $L$ realmente valha 30 torna-se ponto de partida para a temática do quarto encontro. Apresenta-se aos estudantes a descrição desse comportamento por meio da linguagem de limites, e a definição de assíntota horizontal é apresentada. Buscando, num primeiro momento, explorar de forma intuitiva esse conceito, propõe-se a seguinte tarefa, adaptada de Murici et al. (2008), desenvolvida com auxílio do software Geogebra:

Deve-se explorar o comportamento da função racional $f(x)=\frac{a x^{2}+1}{b x^{2}-4}$, variando os parâmetros $a$ e $b$. Para isso, insira no Geogebra os seletores a e b, com intervalos de variação de -5 a 5 . Em seguida, digite a expressão da função na caixa de entrada, e movimente os seletores, conforme as instruções a seguir:

a) Faça $a=0$ e $b=0$. Que tipo de função obtemos?

R. B. E. C. T., vol 6, núm. 1, jan-abr.2013 ISSN - 1982-873X 
b) Faça $a \neq 0$ e $b=0$. Teremos uma classe de funções cujo comportamento conhecemos bem. Que funções são essas? Quando variamos o valor de $a, o$ que se mantém constante e o que varia?

c) Mantenha agora $b=1$. Determine se existem assíntotas horizontais no gráfico da função, escolhendo diferentes valores de a.

d) Mantenha agora $a=2$. Determine se existem assíntotas horizontais no gráfico da função, escolhendo diferentes valores de $b$.

e) Generalize os resultados os itens (c) e (d), descrevendo em que situações existirão assíntotas horizontais, e quais serão elas.

Retomando a discussão sobre a obtenção do resultado 30 , os alunos foram instigados a encontrar uma estratégia para obter esse número sem auxílio do software. Questionados sobre quais seriam outras funções com comportamento final parecido com a função inicial, ou seja, cujo gráfico tem assíntota horizontal, os estudantes chegam à função , cujo comportamento pode ser observado com auxílio do software. Na verdade, o mesmo é usado para explorar a família de funções $f(x)=\frac{c}{x^{n}}$, com $c \in I R$ e $n \in I N$. Tal exploração serve como motivação para a construção, junto aos estudantes, da estratégia para cálculo de limites no infinito de funções racionais a partir da divisão do numerador e do denominador pela maior potência de $x$ do denominador.

Atribuir um sentido preciso à expressão "os valores da função tornam-se tão próximos de um número $L$ quanto queiramos" foi o objetivo do quinto e último encontro. Retomando a situação proposta inicialmente, referente à concentração de sal no tanque após $t$ minutos, propõe-se aos estudantes encontrar qual o tempo mínimo necessário para que essa concentração ultrapasse $29,9 \mathrm{~g} / \mathrm{L}$. Por meio da resolução de uma inequação do 10 grau, obtém-se que esse tempo seja 59800 minutos. Considerar que distância entre a reta $L=30$ e a curva que representa o gráfico da função $C(t)$ não deve ser maior que 0,1 é equivalente a dizer que

$$
\left|\frac{30 x}{200+x}-30\right|<0,1 \text {. }
$$

Tem-se assim uma motivação para a apresentação da definição precisa de limite no infinito, estabelecendo uma transição do conceito informal de limite para uma definição precisa. Assim, à frase informal "tornar-se tão próximo de $L$ quanto queiramos" é atribuído um sentido quantitativo de escolher arbitrariamente um número positivo $\varepsilon$ tal que $|f(x)-L|<\varepsilon$ sempre que $x$ seja maior que um número real $N$. 


\section{Considerações finais}

Apresentamos neste artigo o modo como organizamos um ambiente de aprendizagem para a disciplina de Cálculo Diferencial e Integral na qual os estudantes puderam trabalhar com tarefas para além das habilidades de reprodução e memorização, suscitando habilidades abrangendo níveis de conexão e de reflexão. À luz das ideias propostas pela Educação Matemática Realística, objetivamos oferecer aos estudantes a possibilidade de matematizar, de "re-inventar" matemática.

Partindo de situações "realizáveis", em que o estudante pudesse explorar conceitos de forma intuitiva e organizá-los matematicamente, buscou-se, com auxílio do professor, construir conceitos formalizados.

Nesse ambiente, o conhecimento matemático mostrou-se dinâmico e construído a partir das relações, justificativas, análise e validações estabelecidas pelos envolvidos e não como algo pronto e acabado. Os estudantes se expressaram de forma oral e escrita e justificaram seus pensamentos por meio da exploração de situações, questionamentos e conjecturas e o professor procurou favorecer, valorizar e explorar as explicitações das perspectivas dos estudantes para que os conhecimentos fossem revelados, compartilhados, ressignificados e insights ocorressem.

A situação-problema que trouxemos a título de exemplo teve por objetivo explorar de forma intuitiva os conceitos relacionados ao comportamento final de uma função, ou seja, quando a variável independente cresce ou decresce sem cotas. Nossa experiência em sala de aula corrobora a ideia de ruptura de um contrato didático (SILVA et al., 2002) segundo o qual o estudante responde apenas questões após a explicação da teoria pelo professor.

A comunicação estabelecida na sala de aula entre todos foi peça chave para o estabelecimento de ambiente de aprendizagem com as características apresentadas, o que vai ao encontro às ideias de Skovsmose (2010, p.12): "aprender é uma experiência pessoal, mas ela ocorre em contextos sociais repletos de relações interpessoais" e por conseguinte, "a aprendizagem depende da qualidade do contato nas relações interpessoais que se manifesta durante a comunicação entre os participantes", em particular, no ambiente de sala de aula.

Por fim, consideramos desejável o professor proporcionar um ambiente em que, por meio da comunicação, investigue toda manifestação de seus estudantes, buscando entender como o estudante interpreta uma tarefa, uma vez que, nem o acertar é garantia de um conhecimento e nem o erro indica a sua não existência, pois o sujeito constrói e reconstrói o seu conhecimento em cada situação vivenciada. 


\section{Bibliografía}

ALRO, H.; SKOVSMOSE, O. Diálogo e Aprendizagem m Educação Matemática. 2.ed.

Tradução de Orlando Figueiredo. Belo Horizonte: Autêntica, 2010.

ANTON, H.; BIVENS, I.; DAVIS, S. Cálculo. Porto Alegre: Bookman, 2007. v.1.

BURIASCO, R. L. C. de. Avaliação em Matemática: um estudo das respostas de alunos e professores. 1999. Tese (Doutorado em Educação) - Universidade Estadual Paulista, Marília. 1999.

FREUDENTAL, H. Revisiting Mathematics Education. Netherlands: Kluwer Academic Publishers, 1991.

LANGE, J. de.Framework for classroom assessment in mathematics.Madison: WCER, 72 pp. 1999.

MURUCI, M.L.; GUIMARÃES, L. C.; GIRALDO, V. A. Funções reais: possibilidades em um ambiente de Geometria Dinâmica. In: IV HTEM - Colóquio de História e Tecnologia no Ensino da Matemática, 2008, Rio de Janeiro. Anais... Rio de Janeiro: UFRJ, 2008.

SANTOS, A. R.; BIANCHINI, Waldecir. Aprendendo Cálculo com Maple: Cálculo de uma variável. 1. ed. Rio de Janeiro - RJ: Livros Técnicos e Científicos Editora S.A., 2002. v. 1. 408 p.

SILVA, B. A. at al. Uma ruptura do Contrato Didático no Estudo de Comportamento de Funções. Educação Matemática em Revista. São Paulo, p. 73 - 77, 01 abr. 2002.

REIS, F. da S. A tensão entre rigor e intuição no ensino de cálculo e análise: a visão de professorespesquisadores e autores de livros didáticos. 2001. Tese (Doutorado) - Faculdade de Educação, Universidade Estadual de Campinas, 2001.

VAN DEN HEUVEL-PANHUIZEN, M. V. D. Assessment and Realistic Mathematics Education. Utrecht: CD-ß Press/Freudenthal Institute, Utrecht University. 1996.

André Luis Trevisan: Professor da Universidade Tecnológica Federal do Paraná, câmpus Londrina. Doutor em Educação Matemática pela Universidade Estadual de Londrina. andrelt@utfpr.edu.br.

Marcele Tavares Mendes: Professora da Universidade Tecnológica Federal do Paraná, câmpus Londrina. Doutoranda do Programa de Pós Graduação em Ensino de Ciências e Educação Matemática da Universidade Estadual de Londrina.marceletavares@utfpr.edu.br. 